\title{
DOWNGRADING ADVANCED STAGE MEDICATION RELATED OSTEONECROSIS OF JAW (MRONJ) USING PEDICLED FLAP- TECHNICAL REVIEW WITH CASE REPORT
}

\author{
Srinivasa Rama Chandra ${ }^{1 a^{*}}$ (DD , Holley Tyler J $^{\text {tb }}$, Ruxandra-Gabriela Coropciuc ${ }^{2 c}$ (D) ,Constantinus Politis $2,3 d$ iD
}

'Division of Oral \& Maxillofacial Surgery, Department of Surgery, College of Medicine, Fred and Pamela Buffett Cancer Center, University of Nebraska Medical Center, 984125, Omaha, NE 68198, USA

2Department of Oral \& Maxillofacial Surgery, Faculty of Medicine, University Hospitals Leuven, UZ Leuven, Campus Sint-Rafaël, Kapucijnenvoer 33, BE-3000 Leuven, Belgium

${ }^{3}$ OMFS IMPATH research group, Department of Imaging \& Pathology, Faculty of Medicine, KU Leuven, Campus Sint-Rafaël, Kapucijnenvoer 33, BE-3000

Leuven, Belgium

${ }^{\mathrm{a} M D,}$ BDS, FDSRCS(Eng), FIBCSOMS(Onc-Recon), Assistant Professor

${ }^{b} M D, D D S$, Resident Surgeon

MD, DDS, Staff Member

${ }^{\mathrm{d} M D}, \mathrm{DDS}, \mathrm{MHA}, \mathrm{MM}$, PhD, Professor and Head

\section{ABSTRACT DOI: https://doi.org/10.25241/stomaeduj.2019.6(3).art.6}

Introduction: Medication related osteonecrosis of the jaw (MRONJ) is a locally destructive, and potentially devastating disease process that occurs in patients with a history of antiresorptive or antiangiogenic therapy. A widely accepted practice of surgical intervention in the management of advanced stage MRONJ involves segmental resection of the affected bone. Aim: We propose to downgrade the stage with pedicled flaps for eradication of biofilm and vascular coverage with load sharing or load bearing constructs of the skeleton. As patients that receive antiresorptive or antiangiogenic therapy often have multiple medical comorbidities, this limits their surgical options and precludes them from being able to undergo expansive segmental resections or microvascular free tissue transfers and are left with palliative measures, thus compromising their care.

Summary: Either concept of MRONJ progression- bone metabolism or vascular breakdown is treated with immediate advancement of a pedicled local tissue flap and is performed for soft tissue coverage, thus providing a new vascular envelope and decreasing soft tissue toxicity to halt furtherance of the disease. Submental island flaps, nasolabial flaps, pedicled buccal fat pad flaps, and facial artery musculomucosal flaps have demonstrated success for longer than two years. This technique addresses downgrading MRONJ stage II and III in the mandible as a possible longterm treatment. This unreported innovative approach consists of marginal resection of the involved alveolar bone, while preserving the affected basal bone and subsequently provides reinforcement with a titanium bone plate, decreasing the chance of pathologic fracture.

Keywords: MRONJ; Flap; Pedicled flap; Medication related osteonecrosis of the jaw; Bisphosphonate related osteonecrosis of the jaw.

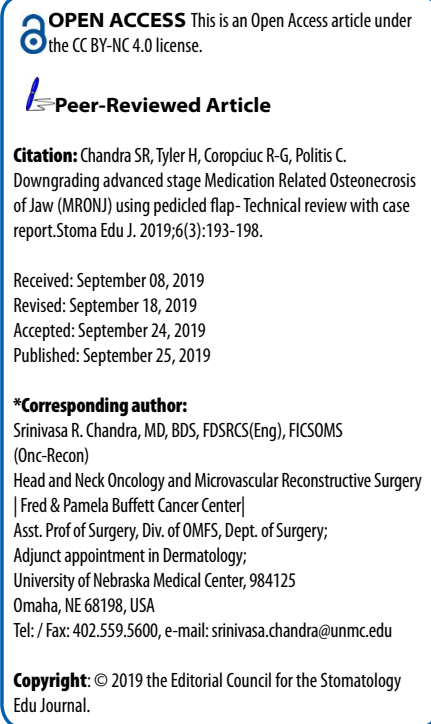

\section{Introduction}

Medication related osteonecrosis of the jaw (MRONJ) is defined as exposed or probable bone in the maxillofacial region without resolution in 8-12 weeks in persons with a history of treatment with an antiresorptive or antiangiogenic therapy who have not received radiation therapy to the jaws [1]. This is an iatrogenic process with an elevated potential for morbidity and decreased quality of life. MRONJ typically occurs in patients with a history of long-term bisphosphonate, RANK ligand inhibitor, or angiogenesis inhibitor use with a precipitating trauma to the maxilla or mandible, such as a dentoalveolar procedure $[1,2]$. MRONJ has a spectrum of presentation, as represented in its staging [1]:

\section{MRONJ Staging}

At Risk: No apparent necrotic bone in patients who have been treated with oral or IV bisphosphonates.

Stage 0: No clinical evidence of necrotic bone, but non-specific clinical findings, radiographic changes and symptoms

Stage 1: Exposed and necrotic bone for more than 8 weeks, or fistulae that probes to bone in patients 
ITable 1.Summary of the stages 0-3 on the left column; middle column is the current and the right column proposes the modification in management especially in the stage $2 \& 3$.

\begin{tabular}{|c|c|c|}
\hline MRONJ Staging & Standard Treatment Strategies & $\begin{array}{l}\text { Proposed Treatment } \\
\text { Strategies }\end{array}$ \\
\hline $\begin{array}{l}\text { At Risk: No apparent necrotic bone in } \\
\text { patient who have been treated with oral } \\
\text { or IV bisphosphonates. }\end{array}$ & $\begin{array}{l}\text { - No Treatment indicated } \\
\text { - Patient education }\end{array}$ & No changes \\
\hline $\begin{array}{l}\text { Stage 0: No clinical evidence of necrotic } \\
\text { bone, but non-specific clinical findings, } \\
\text { radiographic changes and symptoms }\end{array}$ & \begin{tabular}{cc}
\multicolumn{2}{c}{ Systemic management } \\
- & Analgesics \\
- & Antibiotics
\end{tabular} & No changes \\
\hline $\begin{array}{l}\text { Stage 1: Exposed and necrotic bone, or } \\
\text { fistulae that probe to bone in patients } \\
\text { who are asymptomatic and have no } \\
\text { evidence of infection }\end{array}$ & $\begin{array}{l}\text { - Antibacetial mouth rinse } \\
\text { - Clinical follow-up } \\
\text { - Patient education and review of } \\
\text { indications for antiresorptive and } \\
\text { antiangiogenic therapies. }\end{array}$ & No changes \\
\hline $\begin{array}{l}\text { Stage 2: Exposed and necrotic bone, or } \\
\text { fistulae that probe to bone, associated } \\
\text { with infection as evidenced by pain and } \\
\text { erythema in the region of the exposed } \\
\text { bone with or without purulent drainage }\end{array}$ & $\begin{array}{l}\text { - Symptomatic treatment with oral } \\
\text { antibiotics } \\
\text { - Oral antibacterial mouth rise } \\
\text { - Pain control } \\
\text { - Debridement to relieve soft tissue } \\
\text { irritation and infection control }\end{array}$ & $\begin{array}{l}\text { - Symptomatic treatment } \\
\text { with oral antibiotics } \\
\text { - Oral antibacterial mouth } \\
\text { rise } \\
\text { - Pain control } \\
\text { - Debridement of alveolar } \\
\text { bone and immediate } \\
\text { advancement of a pedicled } \\
\text { local tissue flap }\end{array}$ \\
\hline $\begin{array}{l}\text { Stage 3: Exposed and necrotic bone or } \\
\text { fistula that probes to bone in patients } \\
\text { with pain, infection, and one or more of } \\
\text { the following: exposed or necrotic bone } \\
\text { extending beyond the region of the } \\
\text { alveolar bone, resulting in pathologic } \\
\text { fracture, extra-oral fistula, oroantral/ } \\
\text { oronasal communication, or osteolysis } \\
\text { extending to the inferior boarder of the } \\
\text { mandible or sinus floor. }\end{array}$ & $\begin{array}{l}\text { - Antibacterial mouth rinse } \\
\text { - Antibiotic therapy and pain control } \\
\text { - Surgical debridement /resection } \\
\text { for linger term palliation of infection } \\
\text { and pain }\end{array}$ & $\begin{array}{l}\text { - Antibacterial mouth rinse } \\
\text { - Antibiotic therapy and pain } \\
\text { control } \\
\text { - Surgical debridement / } \\
\text { resection of alveolar bone, } \\
\text { leaving basilar bone intact, } \\
\text { placement of a supra or } \\
\text { subperiosteal titanium } \\
\text { bone plate and immediate } \\
\text { advancement of a pedicled } \\
\text { local tissue flap }\end{array}$ \\
\hline
\end{tabular}

ITable 2. The table highlights the advantages to the vascular flap coverage to MRONJ management.

\begin{tabular}{|l|}
\hline Advantages of Vascular Coverage \\
\hline 1. Improved blood supply to underlying bone \\
\hline 2. Improved medication delivery to underlying bone \\
\hline 3. Eradication of chronic biofilm colonization \\
\hline 4. Decreased inflammation \\
\hline 5. Halts disease progression \\
\hline
\end{tabular}

who are asymptomatic and have no evidence of infection

Stage 2: Exposed and necrotic bone, or fistulae that probe to bone, associated with infection as evidenced by pain and erythema in the region of the exposed bone with or without purulent drainage Stage 3: Exposed and necrotic bone or fistula that probes to bone in patients with pain, infection, and one or more of the following: exposed or necrotic bone extending beyond the region of the alveolar bone, resulting in pathologic fracture, extra-oral fistula, oroantral/oronasal communication, or osteolysis extending to the inferior boarder of the mandible or sinus floor.
I Table 3. Key notable points prior to sequestrum removal and vascular coverage of MRONJ.

\begin{tabular}{|l|}
\hline Critical Steps Prior to Vascular Soft Tissue Coverage \\
\hline 1. Obtain cultures \\
\hline $\begin{array}{l}\text { 2. Review imaging to determine the presence of } \\
\text { pathologic fracture or need for internal fixation }\end{array}$ \\
\hline $\begin{array}{l}\text { 3. Biopsy for recurrence of neoplastic process. } \\
\text { Example- recurrence of multiple myeloma }\end{array}$ \\
\hline
\end{tabular}

To date, there is no consensus on the MRONJ stage III treatment protocol.

The current management options range from the non-invasive, antibacterial mouth rinse, systemic treatment with oral antibiotics, and close follow up, to invasive management of potentially extensive debridement/resection of the maxilla or mandible. Conservative therapy is defined as no surgical intervention. This category includes the use of antibacterial mouth rinses and antibiotics and the removal of sequestra without local anesthetics. Ozone therapy and hyperbaric oxygen therapy are considered conservative therapeutic approaches, even though for neither of these evidence-based 


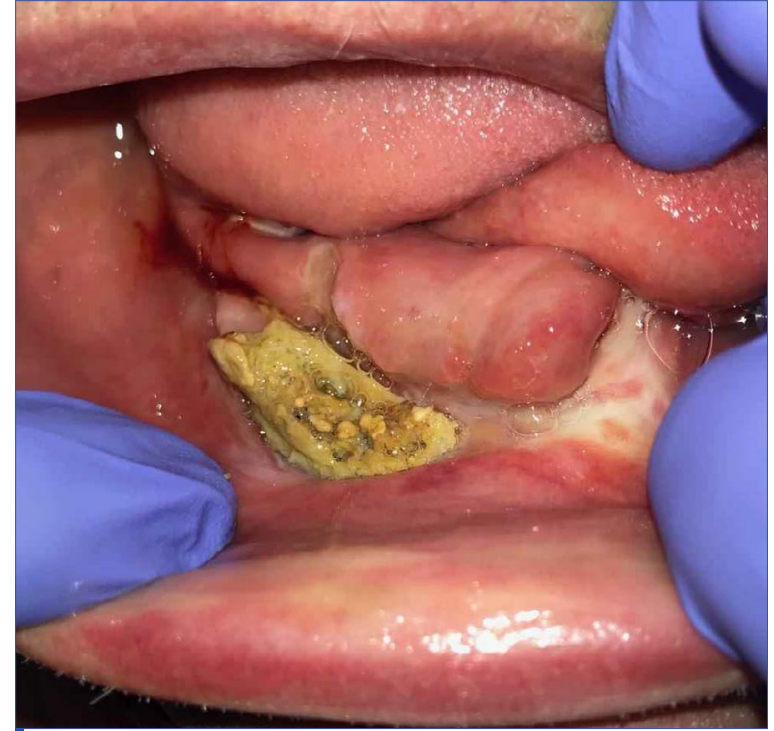

Figure 1. MRONJ and bony sequestrum of right mandible in patient with history of antiangiogenic therapy.

proof of benefit is available. Conservative surgical therapy is defined as a sequestrectomy, without resection or removal of non-sequestrated bone. Whenever no mucoperiostal flap is used a sequestrectomy is considered limited surgical therapy. Invasive surgical treatment includes anything from a sequestrectomy (starting with the use of mucoperiostal flaps), with a resection of the affected bone up to the bleeding margins of bone, to segmental mandibulectomies and reconstructions with pedicled or microvascular free flaps.

Conservative management alone is insufficient to achieve full mucosal healing, but can be useful to stabilize disease progression in patients unfit for surgery. The use of hyperbaric oxygen therapy has no role in MRONJ grade III. The conservative surgical approach provides better results than a purely conservative approach: $75 \%$ achieve an improved condition, and of these, $54 \%$ achieve full mucosal healing. However, this group consists of a relatively small number of patients $(n=48$, distributed over four studies) $[3,4,5]$. The best treatment results for MRONJ stage III are observed in patients treated with invasive surgery. Invasive surgery without microvascular flap reconstruction yields a full mucosal healing rate of $85 \%$, when six studies are combined [6-11]. This approach outperforms the $54 \%$ healing rate achieved with the limited surgical approach. This finding suggests that extensive bony resection up to the bleeding margins is more efficient than a sequestrectomy to achieve full mucosal healing in MRONJ stage III. Invasive surgery with microvascular flap reconstruction yields even better results, with a full mucosal healing rate of $97 \%$ $[12,13]$. However, many patients cannot undergo this kind of procedure, due to underlying comorbidity [14]. Bisphosphonate, RANK ligand inhibitor, and angiogenesis inhibitors are most commonly used for cancer-related conditions, and thus these patients

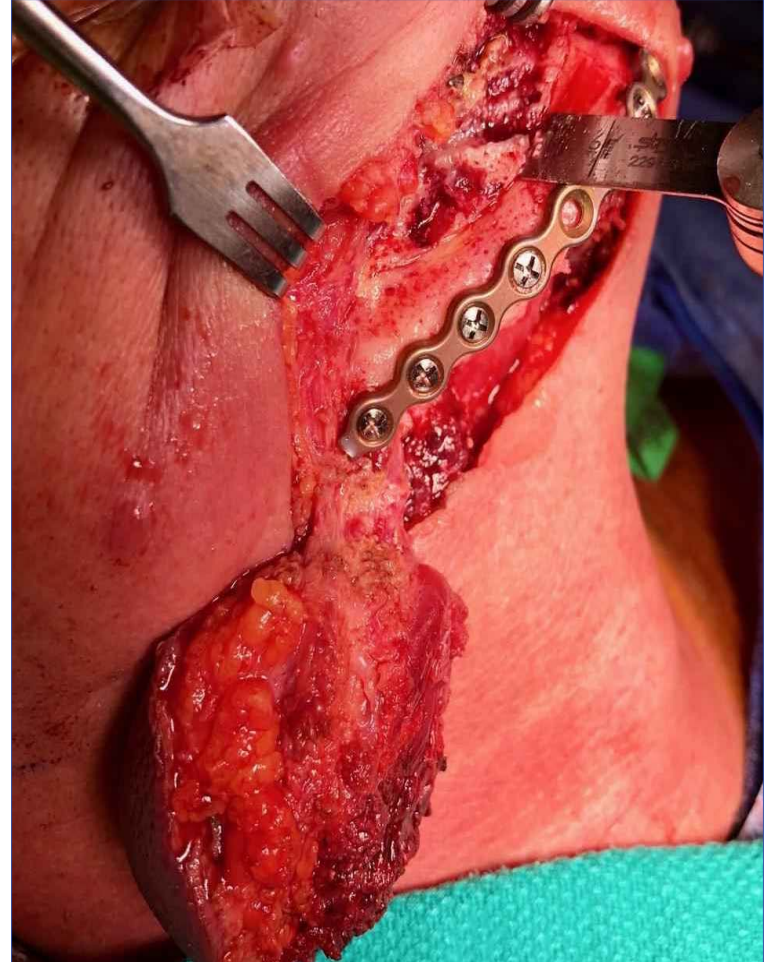

Figure 2. Resection of necrotic alveolar bone is done, basal bone retained can be reinforced by plating (load bearing or sharing as needed) and submental island flap harvested using the same neck incision.

typically have numerous medical co-morbidities that often do not allow them to undergo extensive debridement/resection of the affected bone and reconstruction. Patients who are not able to undergo their indicated surgical treatment typically suffer deterioration of MRONJ and their antiresorptive or antiangiogenic therapy is often discontinued. This leaves the patient vulnerable to advancement of their cancer-related condition and their inadequate treatment allows for progression of MRONJ leading to involvement of previously unaffected bone, pathologic fractures and extra-oral and oronasal/ oroantral fistula development. Soft tissue toxicity has been proposed in the pathogenesis of MRONJ. The mechanism is thought to involve the toxic effects of deposited bisphosphonates to local soft tissue and this might contribute to osteonecrosis of the jaw (ONJ) $[2,15,16]$. The inhibition of a variety of cell types to grow on bone surfaces previously treated with bisphosphonates has been demonstrated [17]. However, no tissue toxicity has been reported with RANK-L inhibitors. Given these considerations, we have developed a less invasive technique for the treatment of MRONJ while providing a vascularized soft tissue envelope and down grading the disease, irrespective of the cause of MRONJ.

\section{Technique}

The current standard practice in the treatment of MRONJ is to resect the affected portion of the jaws until the necrotic portion has been removed and bleeding bone is encountered [18]. As MRONJ is 


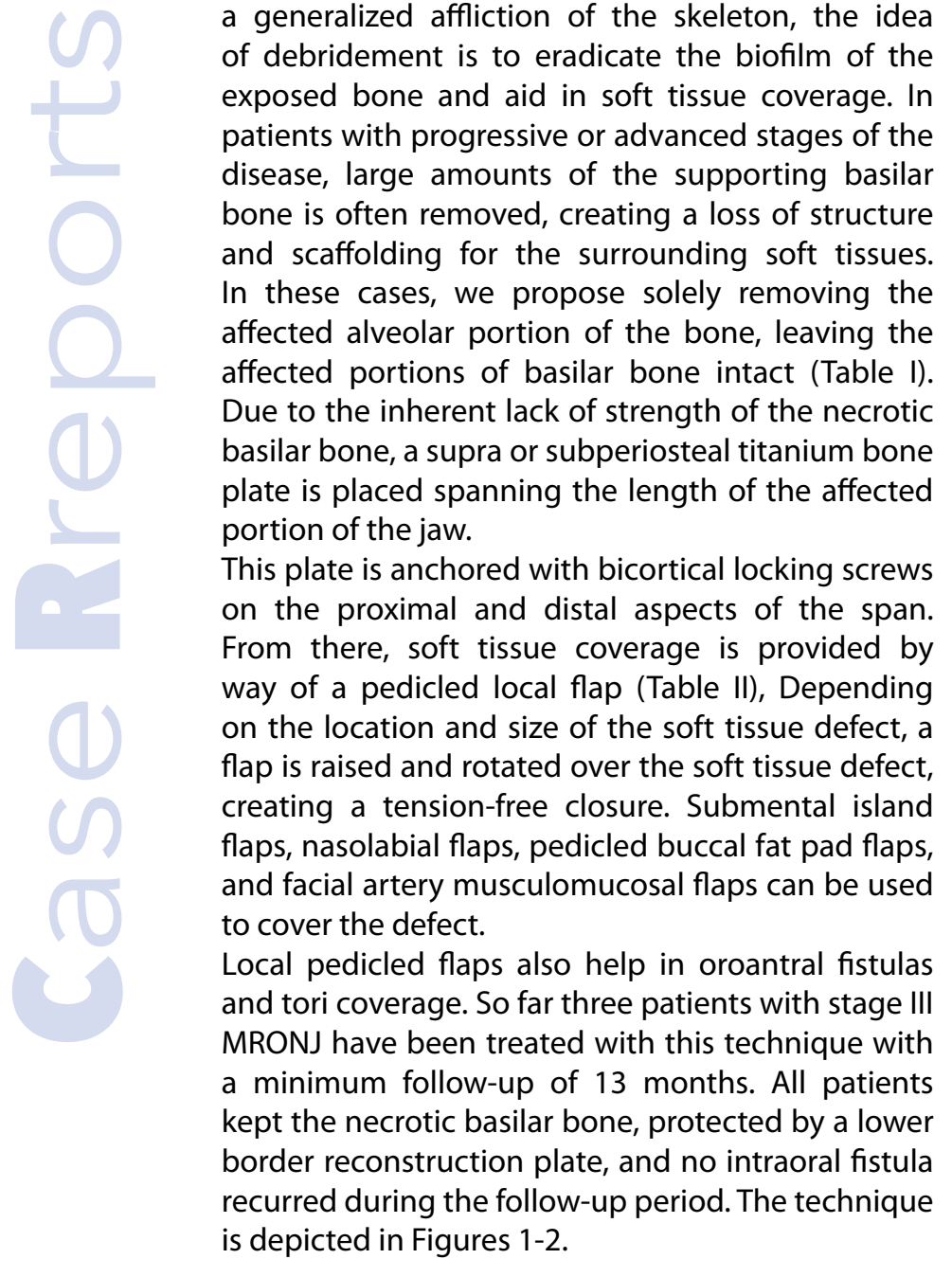

\section{Discussion}

MRONJ has several proposed hypotheses of pathophysiology, including bone remodeling inhibition, inflammation and infection, angiogenesis in inhibition, and immunity disfunction.

Given the fact that MRONJ occurs in patients with a history of antiresorptive and antiangiogenic therapies and a host of different backgrounds most authors agree that the MRONJ pathogenesis is likely multifactorial.

One of the earlier noted hypotheses was that bisphophates, especially nitrogen-containing bisphosphonates, caused direct soft tissue toxicity, inducing apoptosis and decreased proliferation of oral epithelial cells $[2,15]$. Invitro studies demonstrate that nitrogen containing bisphosphonates localize to epithelial tissue and bone and that alendronate is associated with esophageal irritation, requiring special precautions during administration [19]. One of the facets to our proposed technique is to provide a new soft tissue envelope by way of advancing a pedicled flap. This not only provides a more robust blood supply to the underlying bone, but it allows for increased delivery of medications. It also eradicates the chronic colonization of debris and biofilm that causes persistent inflammation. Our observations show that this technique has been able to halt furtherance of the disease.

As previously discussed, MRONJ has a spectrum of presentation, as represented in its staging. Multiple studies have suggested treatment of the early stage MRONJ as more significant debilitation to the quality of life and pathological fractures happen in advanced stages of MRONJ. By removing the overlying infected soft tissue, debriding the alveolar bone and providing a new soft tissue coverage, this technique successfully downgrades MRONJ to a less severe state so that local measures, such as antibacterial mouth wash, are able to keep the symptom manageable.

Several other authors agree that a new vascular soft tissue coverage is essential to the long-term treatment of MRONJ (Table III) [20]. Commonly clinic based plain panoramic imaging in outpatients and cone beam computed tomographic imaging may be adequate to monitor bone status if there is appropriate soft tissue coverage.

Bone isotope studies are more specific for the turnover with biocontamination of the exposed bone. Additionally, osteoporosis from bacterial biofilm burden of the area is reduced from good vascularized soft tissue coverage as proposed here.

\section{Conclusion}

This technique demonstrates a novel approach to MRONJ treatment. Our more conservative technique of alveolar bone debridement, leaving the basilar bone intact, placement of a titanium bone plate for reinforcement and advancement of a local tissue flap for soft tissue coverage is ideal for patients who are unable to undergo a microvascular free tissue transfer or who should not terminate their antiresorptive or antiangiogenic therapy.

\section{Conflict of Interest}

All authors have no conflict of interest to declare.

\section{Funding}

No sources of funding were obtained for this study. 


\section{References}

1. Ruggiero SL, Dodson TB, Fantasia J, et al. American Association of Oral and Maxillofacial Surgeons position paper on medication-related osteonecrosis of the jaw-2014 update. J Oral Maxillofac Surg. 2014;72(10):1938-1956. [CrossRef] Google Scholar Scopus 2. Reid IR, Cornish J. Epidemiology and pathogenesis of osteonecrosis of the jaw. Nat Rev Rheumatol. 2011;8(2):90-96. [CrossRef] Google Scholar Scopus 3. Coropciuc RG, Grisar K, Aerden T, et al. Medicationrelated osteonecrosis of the jaw in oncological patients with skeletal metastases: conservative treatment is effective up to stage 2. Br J Oral Maxillofac Surg. 2017;55(8):787-792. [Full text links] [CrossRef] [PubMed] Google Scholar Scopus 4. Aljohani S, Gaudin R, Weiser J, et al. Osteonecrosis of the jaw in patients treated with denosumab: A multicenter case series. J Craniomaxillofac Surg. 2018;46(9):1515-1525. [Full text links] [CrossRef] [PubMed] Google Scholar Scopus 5. Nisi M, Karapetsa D, Gennai S, et al. Conservative surgical treatment of medication related osteonecrosis of the jaw (MRONJ) lesions in patients affected by osteoporosis exposed to oral bisphosphonates: 24 months followup. J Craniomaxillofac Surg. 2018;46(7):1153-1158. [Full text links] [CrossRef] [PubMed] Google Scholar 6. Lopes RN, Rabelo GD, Rocha AC, et al. Surgical therapy for bisphosphonate-related osteonecrosisof the jaw: six-year experience of a single institution. J Oral Maxillofac Surg. 2015;73(7):1288-1295. [Full text links] [CrossRef] [PubMed] Google Scholar 7. Favia G, Tempesta A, Limongelli L, et al. Medicationrelated osteonecrosis of the jaw: surgical or nonsurgical treatment? Oral Dis. 2018;24(1-2):238-242. [CrossRef] Google Scholar 8. Blus C, Giannelli G, Szmukler-Moncler S, Orru G. Treatment of medication-related osteonecrosis of the jaws (MRONJ) with ultrasonic piezoelectric bone surgery. A case series of 20 treated sites. Oral Maxillofac Surg. 2017;21(1):41-48. [Full text links] [CrossRef] [PubMed] Google Scholar 9. Berrone M, Florindi FU, Carbone V, et al. Stage 3 medicationrelated osteonecrosis of the posterior maxilla: Surgical treatment using a pedicled buccal fat pad flap: Case Reports. J Oral Maxillofac Surg. 2015;73(11):2082-2086. [Full text links] [CrossRef] [PubMed] Google Scholar Scopus 10. Klingelhöffer $C$, Zeman F, Meier J, et al. Evaluation of surgical outcome and influencing risk factors in patients with medication-related osteonecrosis of the jaws. J Craniomaxillofac Surg. 2016;44(10):1694-1699. [Full text links] [CrossRef] [PubMed] Google Scholar Scopus
11. Pichardo SE, Kuijpers SC, Van Merkesteyn JP. Bisphosphonate-related osteonecrosis of the jaws: Cohort study of surgical treatment results in seventy-four stage II/ III patients. J Craniomaxillofac Surg. 2016;44(9):1216-1220. [Full text links] [CrossRef] [PubMed] Google Scholar Scopus 12. Mücke $T$, Jung $M$, Koerdt $S$, et al. Free flap reconstruction for patients with bisphosphonate related osteonecrosis of the jaws aftermandibulectomy.JCraniomaxillofacSurg.2016;44(2):142-147. [Full text links] [CrossRef] [PubMed] Google Scholar Scopus 13. Caldroney S, Ghazali N, Dyalram D, Lubek JE. Surgica resection and vascularized bone reconstruction in advanced stage medication-related osteonecrosis of the jaw. Int J Oral Maxillofac Surg. 2017:46(7):871-876. [Full text links] [CrossRef] [PubMed] Google Scholar Scopus 14. Sacco R, Sacco N, Hamid U, et al. Microsurgical reconstruction of the jaws using vascularised free flap technique in patients with medication-related osteonecrosis: a systematic review. Biomed Res Int. 2018;2018:9858921. [Full text links] [CrossRef] [PubMed] Google Scholar Scopus 15. Reid IR, Bolland MJ, Grey AB. Is bisphosphonateassociated osteonecrosis of the jaw caused by soft tissue toxicity? Bone. 2007;41(3):318-320. [Full text links] [CrossRef] [PubMed] Google Scholar 16. Landesberg R, Cozin M, Cremers S, et al. Inhibition of oral mucosal cell wound healing by bisphosphonates. J Oral Maxillofac Surg 66:839, 2008. J Oral Maxillofac Surg. 2008;66(5):839-847. [Full text links] [CrossRef] [PubMed] Google Scholar Scopus 17. Cornish J, Bava U, Callon K, et al. Bone-bound bisphosphonate inhibits growth of adjacent non-bone cells. Bone. 2011:49(4):710-716. [Full text links] [CrossRef] [PubMed] Google Scholar Scopus 18. Carlson ER, Basile JD. The role of surgical resection in the management of bisphosphonate-related osteonecrosis of the jaws. J Oral Maxillofac Surg. 2009;67(5 Suppl):85-95. [Full text links] [CrossRef] [PubMed] Google Scholar Scopus 19. Watts NB, Diab DL. Long-term use of bisphosphonates in osteoporosis. J Clin Endocrinol Metab. 2010;95(4):1555-1565. [Full text links] [CrossRef] [PubMed] Google Scholar 20. Khan AA, Morrison A, Hanley DA, et al. Diagnosis and management of osteonecrosis of the jaw: A systematic review and international consensus. J Bone Miner Res. 2015:30(1):3-23. [Full text links] [CrossRef] [PubMed] Google Scholar Scopus

\section{Srinivasa Rama CHANDRA \\ MD, BDS, FDSRCS(Eng), FICSOMS(Onc-Recon) \\ Assistant Professor \\ Head and Neck Oncology and Microvascular Reconstructive Surgery \\ Fred \& Pamela Buffett Cancer Center| \\ Division of Oral \& Maxillofacial Surgery \\ Department of Surgery, College of Medicine Adjunct appointment in Dermatology

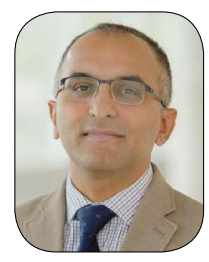

University of Nebraska Medical Center, 984125

Omaha, NE 68198, USA

Dr. Srinivasa Rama Chandra is a Maxillofacial Surgery Specialist in Seattle, Washington. Having more than 24 years of wide experience, especially in Maxillofacial Surgery, Dr. Srinivasa Rama Chandra is affiliated with the Head and Neck Oncological and Microvascular reconstructive surgery at the Fred and Buffett Cancer Center and collaboratively operates with surgical oncologists, neurosurgeons and dermatologists.

Srinivasa Rama Chandra currently works at the Head and Neck Oncology and Reconstructive Microvascular- Oral and Maxillofacial Surgery, University of Nebraska Medical Center. Srinivasa conducts research in Head and Neck Oncology, Oral and Maxillofacial Surgery and Pathology. He specializes in Reconstructive, open skull base access and reconstruction, dermatological pathology and has additional appointment in dermatology. 


\section{Ouestions}

1. MRONJ in which there is exposed and necrotic bone, or fistulae that probes to bone, associated with infection as evidenced by pain and erythema in the region of the exposed bone with or without purulent drainage is:

口a. MRONJ stage 0;

ab. MRONJ stage 1 ;

ac. MRONJ stage 2;

Dd. MRONJ stage 3.

2. Denosumab (monoclonal antibody) inhibits maturation of osteoclasts by binding to and inhibiting:

a. RANK-Ligand;

b. Osteoprotegerin;

ac. WNT-ligand;

ad. Sclerostin.

\section{One of following treatments does not belong to the standard of care in MRONJ:}

口a. Hyperbaric oxygen;

ab. Antibiotics;

ac. Sequestrectomy;

$\square d$. Regional or distant soft tissue flaps.

\section{XGEVA ${ }^{\oplus}$ is a:}

$\square$ a. Nitrogen containing bisphosphonate;

ab. Non-nitrogen nitrogen containing bisphosphonate;

ac. Diphosphonic acid;

$\square d$. Fully human monoclonal antibody to RANKL.

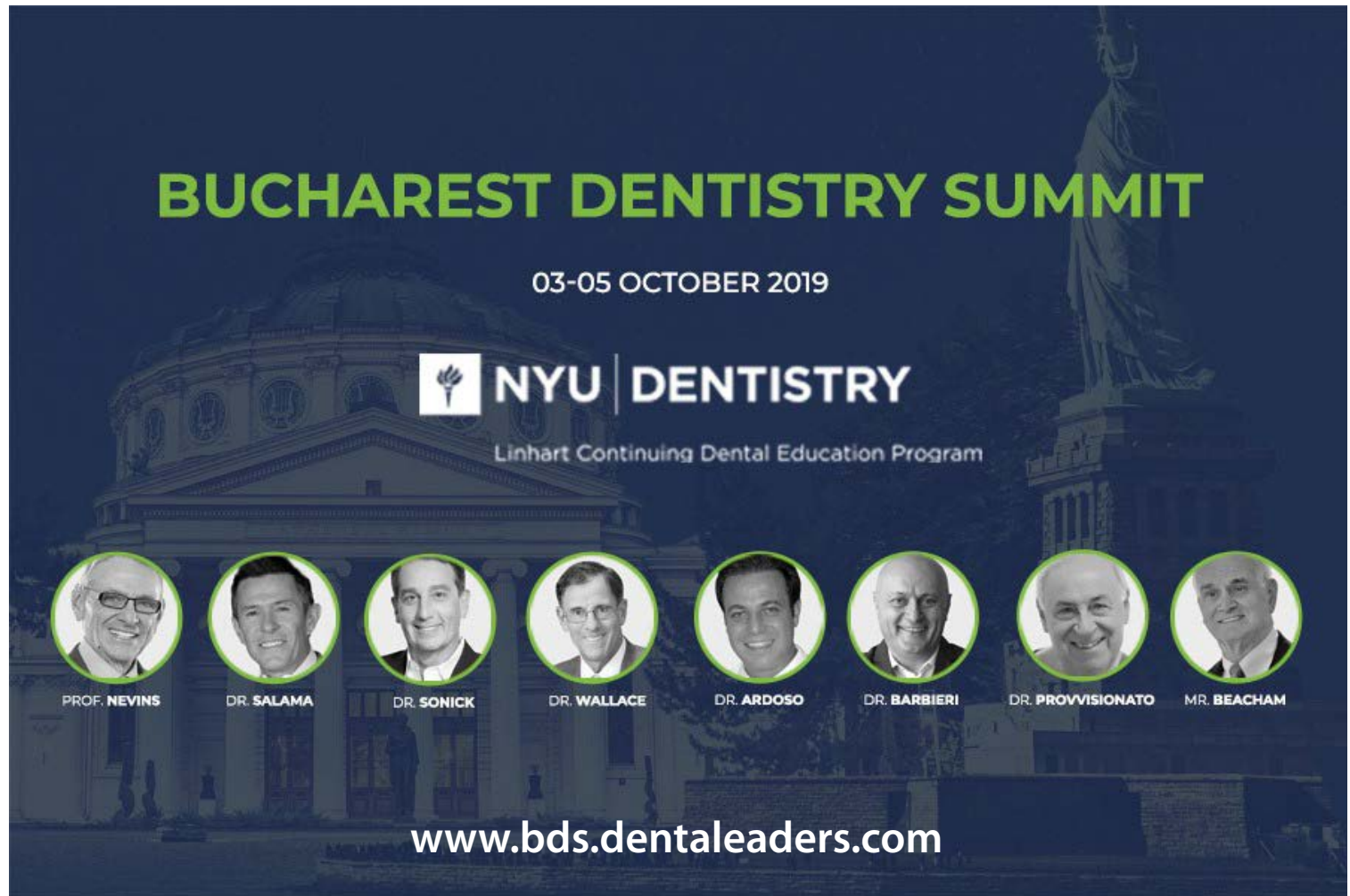

